Article

\title{
$\beta$-Nitroacrylates: New Key Precursors of Indole-2-Carboxylates via Fischer Indole Synthesis
}

\author{
Serena Gabrielli, Deepak Panmand, Roberto Ballini and Alessandro Palmieri *(D)
}

Green Chemistry Group, Chemistry Division, School of Science and Technology, University of Camerino, Via S. Agostino n. 1, 62032 Camerino (MC), Italy; serena.gabrielli@unicam.it (S.G.); dspanmand@gmail.com (D.P.); roberto.ballini@unicam.it (R.B.)

* Correspondence: alessandro.palmieri@unicam.it; Tel.: +39-0737-402-262

Received: 5 November 2019; Accepted: 23 November 2019; Published: 28 November 2019

\begin{abstract}
Indole 2-carboxylates are very important scaffolds that are widely investigated for their activities and are used as key intermediates of biologically active molecules. Herein, we report a new procedure for the preparation of this class of derivatives, via Fischer indole synthesis, starting from $\beta$-nitroacrylates and arylhydrazines. The protocol permits the production of the title targets in satisfactory overall yields, avoids any wasteful aqueous work-up, and has with evident advantages from a sustainability point of view.
\end{abstract}

Keywords: Indoles; $\beta$-nitroacrylates; Fischer indole synthesis; heterocycles; conjugate addition

\section{Introduction}

The indolic system is one of the most important and versatile nitrogen containing heterocycles; it is widely spread in nature, such as in food, flowers, in a multitude of biologically active molecules, and is probably represented as one of the "privileged structures" of the main scaffolds for the discovery of new drug candidates [1,2]. For all these reasons, a growing number of synthetic approaches for its preparation and derivatization have been reported in the literature [3-5]. Nowadays, notwithstanding the development of new methodologies concerning the ex-novo preparation of indoles, the historical Fischer indole synthesis (introduced by Emil Fischer in 1883) remains one of the pillars for the direct production of functionalized indoles (Scheme 1) [6,7].

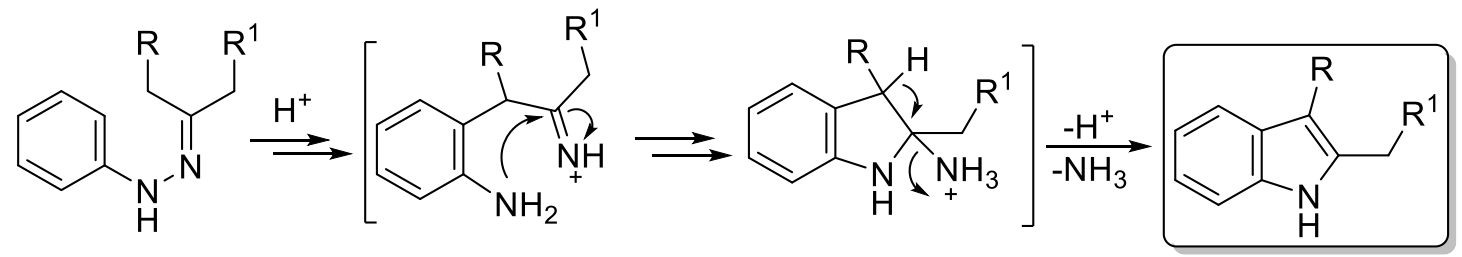

Scheme 1. Fischer indole synthesis.

This reaction is based on the indolization of arylhydrazones under acidic conditions, and over the years, several studies have been done concerning the discovery and use of even-more efficient acid catalysts [8]. However, only few efforts have been directed toward the preparation of arylhydrazones, which are mainly prepared from ketones and arylhydrazines (Scheme 2) [9-11]. 
<smiles>[R]CC(=O)C[R]</smiles>

Scheme 2. Synthesis of arylhydrazones.

While simple ketones are cheap and readily available, the functionalized ones very often require a multistep synthesis and harsh reaction conditions. Among them, $\alpha$-ketoesters are of particular interest since they are key precursors of alkyl indole-2-carboxylates, a very important class of indole that is widely investigated for its activities and is exploited as a strategic intermediate of biologically active targets, such as the NNRTI Delavirdine and its analogues [12-17]. Recently, following our study concerning the use of $\beta$-nitroacrylates $\mathbf{1}$ as a useful building block of heterocyclic systems [18-21], we reported a new protocol for synthesizing 5, starting from 1 and $o$-bromoanilines, based on a palladium catalyzed Heck coupling [22] (Scheme 3, Way b). Now, in continuing this study with the aim of avoiding the use of precious metal (Pd), we found 1 to be a valuable alternative of $\alpha$-ketoesters for the Fischer indole synthesis (Scheme 3, Way a).

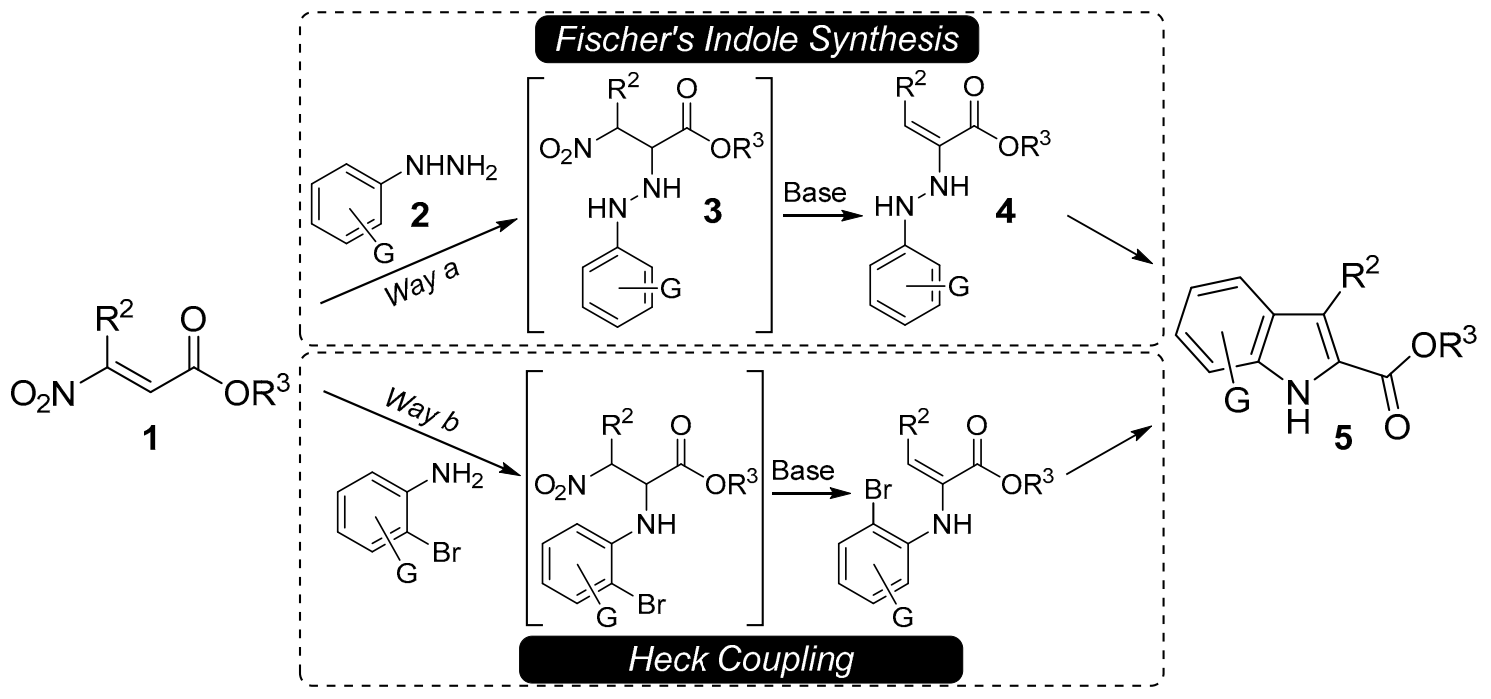

Scheme 3. Synthesis of alkyl indole-2-carboxylates starting from $\beta$-nitroacrylates.

\section{Materials and Methods}

\subsection{General Section}

OXFORD NMR S400, Varian Mercury Plus 400, Oxford, UK, equipped with workstation Sun Blade 150, software VNMRJ 1.1d, and operating system Solaris 9. ${ }^{1} \mathrm{H}$ NMR analyses were recorded at $400 \mathrm{MHz}$ and ${ }^{13} \mathrm{C}$ NMR analyses were recorded at $100 \mathrm{MHz}$. Ir spectra were recorded with a Spectrum Two FT-IR spectrometer, Waltham, MA, USA equipped with ZnSe window, Dynascan Interferometer, detector type $\mathrm{LiTaO}_{3}$, and Spectrum 10 software. Microwave irradiations were performed by Biotage ${ }^{\circledR}$ Initiator. Microanalyses were performed with a CHNS-O analyzer Model EA 1108 from Fisons Instruments. GS-MS analyses were obtained on an Agilent GC(6850N)/MS(5973N), Stevens Creek Blvd, Santa Clara, CA, USA, EI technique (70 eV), GC/MSD software, and an HP-5MS column, 30m, Id $0.25 \mu \mathrm{m}$, film thichness $0.25 \mu \mathrm{m}$. Amberlyst 15 was purchased from Sigma-Aldrich and was purified by soaking it in methanol for $24 \mathrm{~h}$ and then washing it with fresh methanol and THF and dried under a vacuum. 


\subsection{Preparation of Starting Materials}

$\beta$-Nitroacrylates 1 were synthesized by the Henry reaction-elimination process, starting from nitroalkanes and alkyl glyoxalates [23,24]. Arylhydrazines were purchased from Sigma-Aldrich as hydrochloride salts and were converted into the free bases by treatment with potassium carbonate in water [25].

\subsection{General Procedure for the Preparation of Compounds 5}

A mixture of $\beta$-nitroacrylate $1(1 \mathrm{mmol})$ and arylhydrazine $2(1 \mathrm{mmol})$ was stirred, under solvent-free and promoter-free conditions, at room temperature for $2 \mathrm{~h}$. Successively, acetonitrile $(6 \mathrm{~mL})$ and TMG ( $2 \mathrm{mmol}, 0.230 \mathrm{mg})$ were added, and the resulting solution was stirred for a further $4 \mathrm{~h}$. Then, the acetonitrile was removed under a vacuum, and for the purposes of removing the TMG, the reaction crude was filtered through a short pad of silica $(3 \mathrm{~g})$ and washed with ethyl acetate $(25 \mathrm{~mL})$. After evaporation under the vacuum of ethyl acetate, the mixture of tautomers $4,4^{\prime}$, and $\mathbf{4}^{\prime \prime}$ were dissolved in $10 \mathrm{~mL}$ of the appropriate alcohol, treated with $2 \mathrm{~g}$ of Amberlyst 15, and irradiated by the Biotage ${ }^{\circledR}$ Initiator ${ }^{+}$at $90^{\circ} \mathrm{C}$ for $4 \mathrm{~h}$. Finally, the resin was filtered off and it was washed with fresh ethyl acetate $(15 \mathrm{~mL})$ and the crude product 5, which was obtained after removal of the solvent at reduced pressure, and was purified by flash chromatography column (hexane-dichloromethane 6:4).

\section{Results and Discussion}

This new approach (Scheme 3, Way a) involves two different steps: (i) A one-pot Michael addition/elimination process, in which the arylhydrazines 2 reacts with 1 to form adduct 3 , which under basic conditions, eliminates nitrous acid and provides intermediate 4; and (ii) an acidic promoted indolization of 4 into the title target 5 .

\subsection{Optimization of the 1st Step}

In order to optimize the entire protocol, we first investigated the Michael addition/elimination one-pot process using phenylhydrazine $\mathbf{2 a}$ and the $\beta$-nitroacrylate $\mathbf{1} \mathbf{a}$ as reagents. Preliminary studies highlighted the almost quantitative addition of $\mathbf{2 a}$ to $1 \mathbf{a}$ under solvent-free and promoter-free conditions at room temperature ( $2 \mathrm{~h}$ ). Further investigations (in terms of solvents, bases, and reaction temperatures) were dedicated to nitrous acid elimination, and the best result was obtained using two equivalents of TMG in MeCN at room temperature (4 h, entry f). Instead of obtaining the pure adduct $4 a$, a mixture of tautomers $\mathbf{4 a}, \mathbf{4} \mathbf{a}^{\prime}$, and $\mathbf{4} \mathbf{a}^{\prime \prime}$ were isolated in a ratio of approximately 54:13:33. The ratio was calculated by ${ }^{1} \mathrm{H}-\mathrm{NMR}$ on the basis of the characteristic signal of each tautomer, as depicted in Figure 1. Nevertheless, all tautomers were suitable for the Fischer indole synthesis (Table 1).

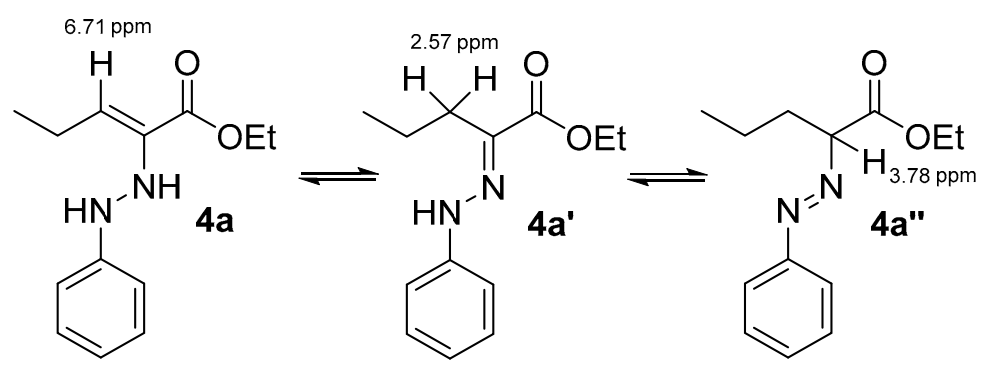

Figure 1. Characteristic ${ }^{1} \mathrm{H}-\mathrm{NMR}$ signal of tautomers $\mathbf{4 a}, \mathbf{4} \mathbf{a}^{\prime}$, and $\mathbf{4} \mathbf{a}^{\prime \prime}$ (tautomeric ratio 54:13:33). 
Table 1. Optimization studies concerning the addition/elimination step.

\begin{tabular}{cccccc} 
(1 eq.) \\
\cline { 3 - 5 }
\end{tabular}

\subsection{Optimization of the 2 nd Step}

Successively, we faced off the indolization of tautomers $4 a-a^{\prime \prime}$ into the alkyl indole-2-carboxylate 5a. In this context, we first performed the addition/elimination one-pot process, then the TMG was removed by fast filtration through a short pad of Silica, and finally, after the removal of the solvent under a vacuum, the crude 4a-a" were subjected to a variety of acidic conditions. Initially, inspired by the literature, we tested PPA, $\mathrm{ZnCl}_{2} / \mathrm{AcOH}, \mathrm{SOCl}_{2} / \mathrm{EtOH}$, and $p$-toluenesulfonic acid/EtOH [26-29]. Only the latter system was efficient for the indolization reaction (3eq. $p-\mathrm{TsOH}, \mathrm{EtOH}$, reflux, $8 \mathrm{~h}$, $32 \%$ ). Based on this result and following our studies concerning the use of heterogeneous systems, we repeated the reaction using $1 \mathrm{~g} / \mathrm{mmol}$ of Amberlyst 15, a sulfonic acid type based upon a styrene-DVB copolymer [30]. Under these conditions, 5a was recovered in a similar yield (30\%), but with the remarkable advantage of minimizing the work-up step to an easy filtration, thus avoiding the classic tedious and wastefully aqueous work-up. Further tests permitted the optimization of reaction conditions (Table 2), and the best yield of $\mathbf{5 a}$ (over the two steps) was recorded, under microwave irradiation at $90{ }^{\circ} \mathrm{C}$ for $4 \mathrm{~h}$, using $2 \mathrm{~g} / \mathrm{mmol}$ of Amberlyst 15 (Entry $k, 54 \%$ ). 
Table 2. Optimization studies concerning the indolization step.

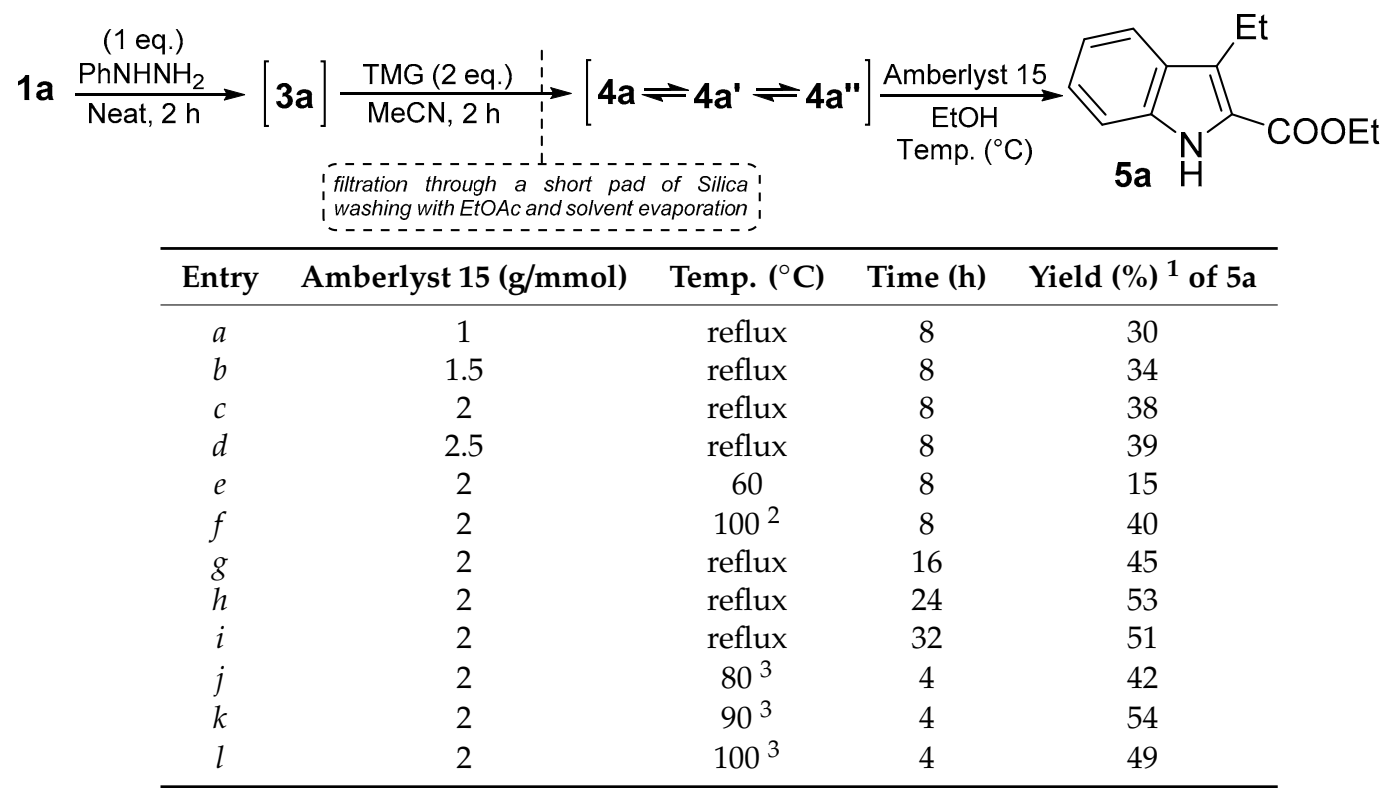

${ }^{1}$ Overall yield of the pure isolated product. ${ }^{2}$ Reaction performed in a sealed vessel. ${ }^{3}$ Reaction performed in a sealed vessel under microwave irradiation.

\subsection{Substrate Scope Investigation}

Lastly, to achieve the aim of verifying the generality of our protocol, we tested a variety of $\beta$-nitroacrylates and arylhydrazines under the optimized reaction conditions (Table 3). In all cases, the products were isolated from satisfactory to good overall yields (38-55\%), even in the presence of versatile and reactive functionalities. In particular, it was possible to prepare indoles functionalized on the C-3 chain that were suitable for further manipulations, such as $\mathbf{5 e - g}$ and $5 \mathbf{j}$, which contained a phenyl ring, a double and triple bond, and an ester group, respectively.

Table 3. Synthesis of indoles $5 \mathbf{a}-\mathbf{m}$.

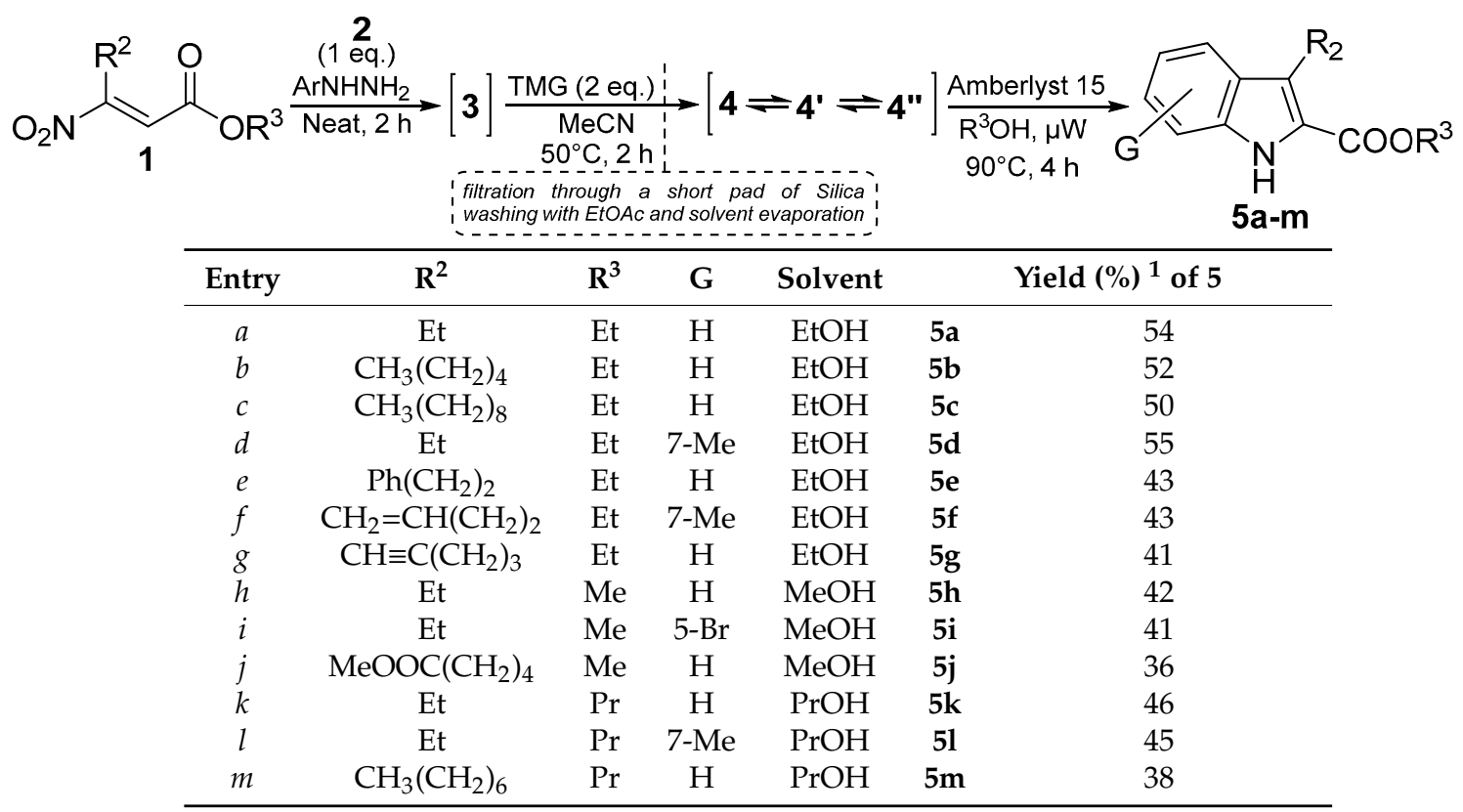

${ }^{1}$ Overall yield of the pure isolated product. 
It is important to highlight that, in order to prevent the transesterification reaction at C-2, the indolization was conducted using the same alcohol $\left(\mathrm{R}^{3} \mathrm{OH}\right)$ of the ester moiety. Detailed spectroscopic data for compounds 5a-m are included in the Supplementary Materials.

\section{Conclusions}

In conclusion, we disclosed a new, important application of $\beta$-nitroacrylates as a valuable alternative of $\alpha$-ketoesters for synthesizing alkyl indole-2-carboxylates, which were key and useful intermediates of biologically active molecules. The method involved two easy steps and afforded title targets with a good substrate scope generality and satisfactory overall yields. Moreover, thanks to the possibility of removing the TMG by an easy filtration through the silica (first step), and the use of heterogeneous Amberlyst 15 in the second step, it was possible to avoid the typical tedious and wasteful aqueous work-up, with evident advantages from a sustainability point of view.

Supplementary Materials: The following are available online at http://www.mdpi.com/2076-3417/9/23/5168/s1, Spectroscopic Data.

Author Contributions: Conceptualization, S.G. and D.P.; methodology, S.G.; investigation, D.P.; validation, S.G. and D.P.; data curation, S.G.; writing—original draft preparation, A.P.; writing-review and editing, A.P.; supervision, R.B.; project administration, A.P.; funding acquisition, A.P.

Funding: This research received no external funding.

Acknowledgments: The authors thank the University of Camerino for financial support.

Conflicts of Interest: The authors declare no conflict of interest.

\section{Abbreviations}

The following abbreviations are used in this manuscript:

TMG

DBU

PS-TBD

PS-Carbonate

NNRTI

PPA
1,1,3,3-Tetramethylguanidine

1,5-Diazabiciclo[5.4.0]undec-5-ene

1,5,7-Triazabicyclo[4.4.0]dec-5-ene bound to polystyrene

(Sigma-Aldrich code: 01961)

Carbonate on polymer support (Sigma-Aldrich code: 21850)

Non-nucleoside reverse transcriptase inhibitor

Poly Phosphoric Acid

\section{References}

1. De Sá Alves, F.R.; Barreiro, E.J.; Fraga, C.A. From nature to drug discovery: The indole scaffold as a 'privileged structure'. Mini Rev. Med. Chem. 2009, 9, 782-793. [CrossRef] [PubMed]

2. Lancianesi, S.; Palmieri, A.; Petrini, M. Synthetic approaches to 3-(2-nitroalkyl) indoles and their use to access tryptamines and related bioactive compounds. Chem. Rev. 2014, 114, 7108-7149. [CrossRef] [PubMed]

3. Gribble, G.W. In Indole Ring Synthesis: From Natural Products to Drug Discovery; Wiley-VCH: Chichester, UK, 2016.

4. Palmieri, A.; Gabrielli, S.; Lanari, D.; Vaccaro, L.; Ballini, R. A New one-pot synthesis of polysubstituted indoles from pyrroles and $\beta$-nitroacrylates. Adv. Synth. Catal. 2011, 353, 1425-1428. [CrossRef]

5. Humphrey, G.R.; Kuethe, J.T. Practical methodologies for the synthesis of indoles. Chem. Rev. 2006, 106, 2875-2911. [CrossRef]

6. Fischer, E.; Jourdan, F. The hydrazone of pyruvic acid. Ber. Dtsch. Chem. Ges. 1883, 16, 2241-2245. [CrossRef]

7. Fischer, E.; Hess, O. The synthesis of indole derivatives. Ber. Dtsch. Chem. Ges. 1884, 17, 559-568. [CrossRef]

8. Heravi, M.M.; Rohani, S.; Zadsirjan, V.; Zahedi, N. Fischer indole synthesis applied to the total synthesis of natural products. RSC Adv. 2017, 7, 52852-52887. [CrossRef]

9. Kiasat, A.R.; Kazemi, F.; Nourbakhsh, $\mathrm{K} . \mathrm{H}_{2} \mathrm{SO}_{4} / \mathrm{SiO}_{2}$ as an efficient catalyst for the preparation of phenylhydrazones and 2,4-dinitrophenylhydrazones under solvent-free conditions. Phosphorus Sulfur Silicon Relat. Elem. 2004, 179, 569-573. [CrossRef] 
10. Polshettiwar, V.; Varma, R.S. Polystyrene sulfonic acid-catalyzed greener synthesis of hydrazones in aqueous medium using microwaves. Tetrahedron Lett. 2007, 48, 5649-5652. [CrossRef]

11. Zhang, M.; Shang, Z.-R.; Li, X.-T.; Zhang, J.-N.; Wang, Y.; Li, K.; Li, Y.-Y.; Zhang, Z.-H. Simple and efficient approach for synthesis of hydrazones from carbonyl compounds and hydrazides catalyzed by meglumine. Synth. Commun. 2017, 47, 178-187. [CrossRef]

12. Sudhakara, A.; Jayadevappa, H.; Mahadevan, K.M.; Hulikal, V. Efficient synthesis of 2-ethoxycarbonyl indoles. Synth. Commun. 2009, 39, 2506-2515. [CrossRef]

13. Brands, M.; Ergüden, J.-K.; Hashimoto, K.; Heimbach, D.; Schröder, C.; Siegel, S.; Stasch, J.-P.; Weigand, S. Novel, selective indole-based ECE inhibitors: Lead optimization via solid-phase and classical synthesis. Bioorg. Med. Chem. Lett. 2005, 15, 4201-4205. [CrossRef] [PubMed]

14. Ueda, S.; Kato, M.; Inuki, S.; Ohno, H.; Evans, B.; Wang, Z.-X.; Peiper, S.C.; Izumi, K.; Kodama, E.; Matsuoka, M. Identification of novel non-peptide CXCR4 antagonists by ligand-based design approach. Bioorg. Med. Chem. Lett. 2008, 18, 4124-4129. [CrossRef] [PubMed]

15. Romero, D.L.; Morge, R.A.; Genin, M.J.; Biles, C.; Busso, M.; Resnick, L.; Althaus, I.W.; Reusser, F.; Thomas, R.C.; Tarpleyt, W.G. Bis(heteroary1)piperazine (BHAP) reverse transcriptase inhibitors: Structure-activity relationships of novel substituted indole analogues and the identification of 1-[(5-methanesulfonamido-1H-indol-2-yl)-carbonyl]-4-[3-[(1-methylethyl)amino]-pyridinyl]piperazine monomethanesulfonate (U-90152S), a second-generation clinical candidate. J. Med. Chem. 1993, 36, 1505-1508. [PubMed]

16. Don, M.-J.; Lewis, D.F.V.; Wang, S.-Y.; Tsai, M.-W.; Ueng, Y.-F. Effect of structural modification on the inhibitory selectivity of rutaecarpine derivatives on human CYP1A1, CYP1A2, and CYP1B1. Bioorg. Med. Chem. Lett. 2003, 13, 2535-2538. [CrossRef]

17. Urwyler, S.; Floersheim, P.; Roy, B.L.; Koller, M. Drug design, in vitro pharmacology, and structure-activity relationships of 3-acylamino-2-aminopropionic acid derivatives, a novel class of partial agonists at the glycine site on the N-methyl-d-aspartate (NMDA) receptor complex. J. Med. Chem. 2009, 52, 5093-5107. [CrossRef] [PubMed]

18. Ballini, R.; Gabrielli, S.; Palmieri, A. $\beta$-Nitroacrylates as an emerging, versatile class of functionalized nitroalkenes for the synthesis of a variety of chemicals. Curr. Org. Chem. 2010, 14, 65-83. [CrossRef]

19. Gabrielli, S.; Chiurchiù, E.; Palmieri, A. $\beta$-Nitroacrylates: A versatile and growing class of functionalized nitroalkenes. Adv. Synth. Catal. 2019, 361, 630-653. [CrossRef]

20. Gabrielli, S.; Giardinieri, A.; Sampaolesi, S.; Ballini, R.; Palmieri, A. A new one-pot synthesis of quinoline-2-carboxylates under heterogeneous conditions. Molecules 2016, 21, 776. [CrossRef]

21. Chiurchiù, E.; Patehebieke, Y.; Gabrielli, S.; Ballini, R.; Palmieri, A. $\beta$-Nitroacrylates as starting materials of thiophene-2-carboxylates under continuous flow conditions. Adv. Synth. Catal. 2019, 361, 2042-2047. [CrossRef]

22. Palmieri, A.; Gabrielli, S.; Maggi, R.; Ballini, R. $\beta$-Nitroacrylates as useful building blocks for the synthesis of alkyl indole-2-carboxylates. Synlett 2014, 25, 128-132. [CrossRef]

23. Ballini, R.; Fiorini, D.; Palmieri, A. Nitroalkanes and ethyl glyoxalate as common precursors for the preparation of both $\beta$-keto esters and $\alpha, \beta$-unsaturated esters. Tetrahedron Lett. 2004, 45, 7027-7029. [CrossRef]

24. Palmieri, A.; Gabrielli, S.; Ballini, R. Low impact synthesis of $\beta$-nitroacrylates under fully heterogeneous conditions. Green Chem. 2013, 15, 2344-2348. [CrossRef]

25. Dey, R.; Kumar, P.; Banerjee, P. Lewis acid catalyzed annulation of cyclopropane carbaldehydes and aryl hydrazines: Construction of tetrahydropyridazines and application toward a one-pot synthesis of hexahydropyrrolo[1,2-b]pyridazines. J. Org. Chem. 2018, 83, 5438-5449. [CrossRef]

26. Bie, J.; Liu, S.; Li, Z.; Mu, Y.; Xu, B.; Shen, Z. Discovery of novel indole derivatives as allosteric inhibitors of fructose-1,6-bisphosphate. Eur. J. Med. Chem. 2015, 90, 394-405. [CrossRef] [PubMed]

27. Jagasia, R.; Jacob-Roetne, R.; Peters, J.-U.; Wichmann, J. Indol-Carboxamide Derivatives. Patent WO2015036412 (A1), 19 March 2015.

28. Yasui, E.; Wada, M.; Takamura, N. Novel approach to arylhydrazones, the precursor for Fischer indole synthesis, via diazo esters derived from $\alpha$-amino acid esters. Tetrahderon Lett. 2006, 47, 743-746. [CrossRef] 
29. Kostenis, E.; Spinrath, A.; Hennen, S.; Peters, L.; Müller, C.E.; Akkari, R.; Baqi, Y.; Ritter, K. GPR 17 Agonists and Screening Assay. Patent EP2567698 (A1), 7 January 2013.

30. Pal, R.; Sarkar, T.; Khasnobis, S. Amberlyst-15 in organic synthesis. ARKIVOC 2012, 2012, 570-609. [CrossRef] 